\title{
ANALYSIS AND CONTROL OF OFFBOARD BIDIRECTIONAL PLUG - IN ELECTRIC VEHICLE (PEV) CHARGER FOR VEHICLE TO GRID OPERATION
}

\author{
J. O. Haruna ${ }^{1}$ and S. O. Sanni2,*

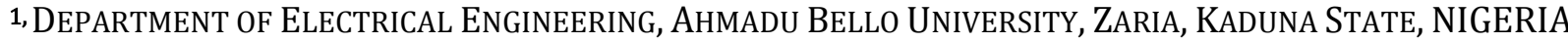

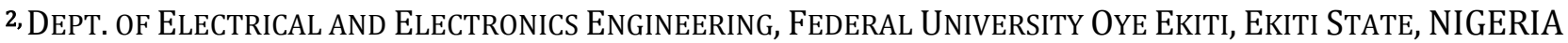 \\ E-mail addresses:1jharuna@abu.edu.ng, ${ }^{2}$ shereefdeen.sanni@fuoye.edu.ng
}

\begin{abstract}
This paper presents an analysis of off board bidirectional Plug in Electric Vehicle (PEV) Charger. Since, normally, the control command for such chargers are given in terms of desired real and reactive power, a model of the system is formulated directly in terms of these variables. A detailed steady state analysis of the system is presented for the entire possible range of operation and for a given battery state of charge (SOC) rather than selecting points of operation a priori. This result shows the various possibilities of the system and informs further structural studies of the system and the design of controllers to meet the desired control objectives.
\end{abstract}

Keywords: Battery charger, electric vehicle, natural variables, vehicle to grid

\section{INTRODUCTION}

Modern day transportation depends largely on fossil fuel. This dependence will rise by about $44 \%$ by 2035 [1] with the attendant cost on the environment. Alternative vehicle technologies are being developed to regulate the effect of transportation oil consumption; the most promising of these alternative vehicle technologies is the electric vehicle. PEV stands for plug in electric vehicle. In the development of PEV battery charging system, a major concern is the impact of largescale use of PEVs on the reliability and operation of the utility. In this regard, PEV battery charging system are conceived to serve a dual purpose: to provide battery charging and to support the utility grid this is the concept of vehicle to grid (V2G) operation.

The two methods (onboard and offboard) of charging PEVs can provide V2G possibilities. The onboard charger is considered to have the advantage of compensating for reactive power very close to the residential load and therefore more efficient and also involve lower installation cost [2]. However, this method would not readily support a long distance travel; it is also limited for the compensation it can provide. Moreover, it cannot supply the kind of support the utility might require. Offboard chargers provide all of these benefits. Reference [3] studied an offboard bidirectional PEV charger for V2G reactive power operation. Recent works have focused on energy management in a V2G scenario [4-6] and the electricity market [7]. It is desirable to design PEVs with both real and reactive power support for the grid, however majority of the work in this area have focused on reactive power support only. This is due to the effect of a bi-directional flow of real power on battery life [3]. Providing this capability with PEVs remains a target of ongoing research. While different battery technologies are being developed to meet this requirement, in the interim an analysis of a PEV system with such a capability is desirable. This analysis will show the possibilities and indeed provide insight of possible operating state for battery designers. This paper presents the analysis of PEV with real and reactive power V2G support employing a mathematical model that will make for easy control.

\section{SYSTEM MODEL}

The studied system is shown in Figure 1. It comprises of a three-phase bi - directional ac to dc converter connected back to back with a bi - directional dc-to-dc converter. The battery is modeled by the equivalent circuit model shown in Figure 1. Between the battery and the bi - directional dc - dc converter is a line modelled by its resistance and inductance. The studied system in Figure 1 is modelled in the qd synchronous reference frame. 


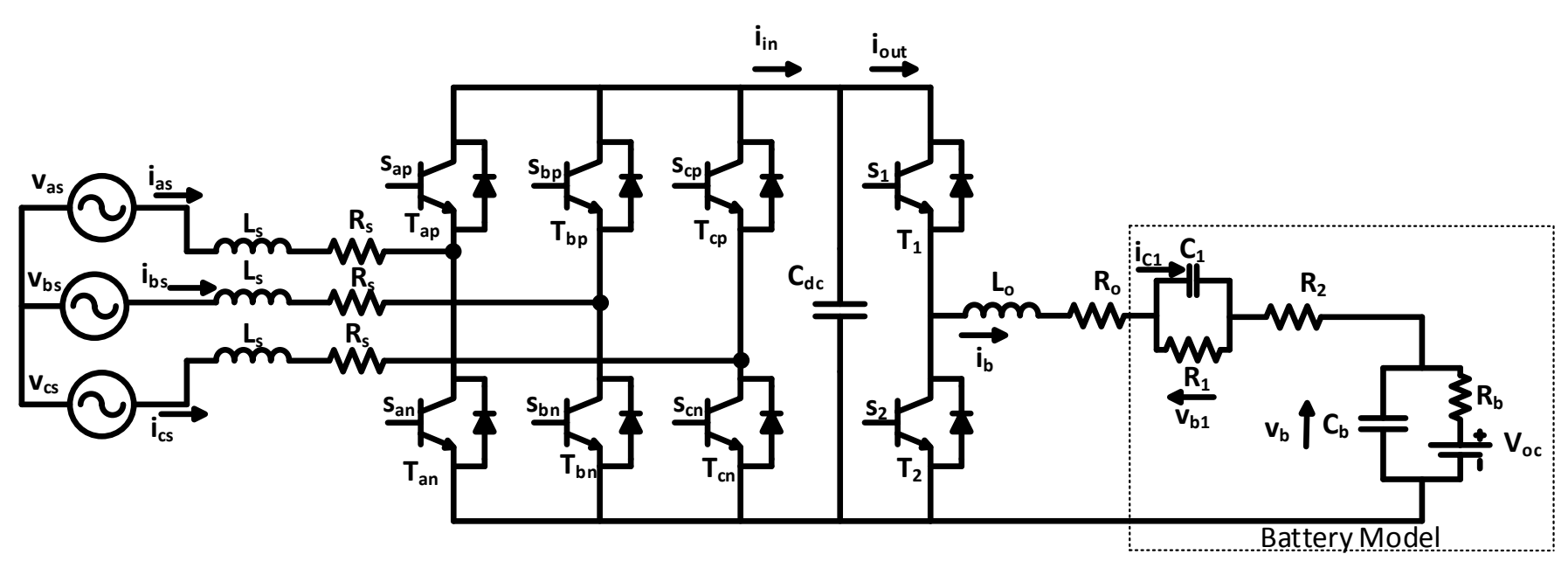

Figure 1: Study system

A three phase variable $f_{a b c}$ can be transformed to the arbitrary reference frame variable $f_{q d o}$ according to:

$$
\boldsymbol{f}_{q d o}=\boldsymbol{K}_{s} \boldsymbol{f}_{\boldsymbol{a b c}} \quad \text { hence } \boldsymbol{f}_{\boldsymbol{a b c}}=\boldsymbol{K}_{\boldsymbol{s}}^{-1} \boldsymbol{f}_{q d o}
$$

Where the transformation matrices are given by:

$$
\begin{gathered}
K_{s}=\frac{2}{3}\left[\begin{array}{ccc}
\cos \theta_{e} & \cos \left(\theta_{e}-\beta\right) & \cos \left(\theta_{e}+\beta\right) \\
\sin \theta_{e} & \sin \left(\theta_{e}-\beta\right) & \sin \left(\theta_{e}+\beta\right) \\
\frac{1}{2} & 1 & 1 \\
K_{s}^{-1}= & \overline{2}
\end{array}\right], \\
\left.\operatorname{coc} \begin{array}{ccc}
\cos \theta_{e} & \sin \theta_{e} & 1 \\
\cos \left(\theta_{e}-\beta\right) & \sin \left(\theta_{e}-\beta\right) & 1 \\
\cos \left(\theta_{e}+\beta\right) & \sin \left(\theta_{e}+\beta\right) & 1
\end{array}\right] \\
\text { and } f_{a b c}=\left[\begin{array}{l}
f_{a} \\
f_{b} \\
f_{c}
\end{array}\right] ; f_{q d o}=\left[\begin{array}{l}
f_{q} \\
f_{d} \\
f_{o}
\end{array}\right]
\end{gathered}
$$

$\theta_{e}=\int \omega_{e} d t$ is the reference frame angle. $\theta_{e}=\theta_{e e}+$ $\theta_{e o}, \theta_{e o}$ is the initial angle of the reference frame and $\beta=\frac{2 \pi}{3}$.

Given a three phase balanced grid voltage as:

$$
\left\{\begin{array}{l}
v_{a}=V_{m} \cos \theta_{s} \\
v_{b}=V_{m} \cos \left(\theta_{s}-\beta\right) \\
v_{c}=V_{m} \cos \left(\theta_{s}+\beta\right)
\end{array}\right.
$$

where $\theta_{s}=\theta_{s s}+\theta_{s o} ; \theta_{s o}$ being the initial angle.

Transforming the grid voltages to the arbitrary reference frame will results in

$$
\left\{\begin{array}{l}
v_{q s}=V_{m} \cos \left(\theta_{e}-\theta_{s}\right) \\
v_{d s}=-V_{m} \sin \left(\theta_{e}-\theta_{s}\right) \\
v_{o s}=0
\end{array}\right.
$$

In the synchronous reference frame and if the angles are aligned such that the initial angle of the reference frame is equal to the initial angle of the voltages then $\theta_{e}=\theta_{s}$ and

$$
\mathrm{v}_{\mathrm{qs}}=\mathrm{V}_{\mathrm{m}} ; \mathrm{v}_{\mathrm{ds}}=0
$$

Where $V_{m}$ is the peak value of the source voltage.
Now, the real power and reactive power are given in the qd frame as:

$$
\begin{aligned}
& \mathrm{P}=\frac{3}{2}\left(\mathrm{v}_{\mathrm{qs}} \mathrm{I}_{\mathrm{qs}}+\mathrm{v}_{\mathrm{ds}} \mathrm{I}_{\mathrm{ds}}\right) \\
& \mathrm{Q}=\frac{3}{2}\left(-\mathrm{v}_{\mathrm{ds}} \mathrm{I}_{\mathrm{qs}}+\mathrm{v}_{\mathrm{qs}} \mathrm{I}_{\mathrm{ds}}\right)
\end{aligned}
$$

Where $I_{q s}$ and $I_{d s}$ are the qd - reference frame currents Therefore, by substituting (4) in (5) and (6)

$$
\mathrm{I}_{\mathrm{qs}}=\frac{2 \mathrm{P}}{3 \mathrm{~V}_{\mathrm{m}}} \text { and } \mathrm{I}_{\mathrm{ds}}=\frac{2 \mathrm{Q}}{3 \mathrm{~V}_{\mathrm{m}}}
$$

From Figure 1, by applying KVL and KCL, the dynamic equation of the three phase bi - directional ac - dc converter can be written in compact form as:

$$
\begin{gathered}
v_{a b c s}=R_{s} I_{a b c s}+L_{s} p I_{a b c s}+\frac{V_{d c}}{2}\left(2 s_{a b c p}-[1]\right) \\
C_{d c} p V_{d c}=I_{\text {in }}-I_{\text {out }}
\end{gathered}
$$

where $I_{\text {in }}=\boldsymbol{s}_{\text {abcp }}^{\boldsymbol{T}} \boldsymbol{I}_{\text {abcs }}$ and $I_{\text {out }}=d_{1} I_{b}$.

also $\boldsymbol{v}_{\text {abcs }}=\left[\begin{array}{c}v_{a} \\ v_{b} \\ v\end{array}\right]$ are the three phase grid voltage;

$\boldsymbol{I}_{\boldsymbol{a b c s}}=\left[\begin{array}{c}I_{a s} \\ I_{b s} \\ I_{c s}\end{array}\right]$ are the three phase grid currents;

$\boldsymbol{s}_{\text {abcp }}=\left[\begin{array}{c}S_{a p} \\ s_{b p} \\ s_{c p}\end{array}\right]$ are the switching functions and

$\boldsymbol{R}_{\boldsymbol{s}}=\left[\begin{array}{ccc}R_{s} & 0 & 0 \\ 0 & R_{s} & 0 \\ 0 & 0 & R_{s}\end{array}\right], \boldsymbol{L}_{\boldsymbol{s}}=\left[\begin{array}{ccc}L_{s} & 0 & 0 \\ 0 & L_{s} & 0 \\ 0 & 0 & L_{s}\end{array}\right]$ are the line

resistance and inductances, $p=\frac{d}{d t}, d_{1}$ is the cycle, $a^{T}$ is the transpose of $a$

$\boldsymbol{s}_{\boldsymbol{a b c \boldsymbol { p }}}=\frac{1}{2}\left(\boldsymbol{m}_{\boldsymbol{a b c \boldsymbol { p }}}+1\right)$ where $m_{a b c p}$ are the actual modulation signals for the converter.

Substituting relevant parameters into (8) and (9) and transforming to the $\mathrm{qd}$ - reference frame and then substituting (7) into the resulting equation, the $\mathrm{qd}$ 
model for the three phase converter and the dc link is obtained in terms of the real and reactive power of the grid as (10) - (12) while (13) - (15) gives the model of the $\mathrm{dc}-\mathrm{dc}$ converter and the battery.

$$
\begin{array}{r}
p \mathrm{P}=-\frac{\mathrm{R}_{\mathrm{s}}}{\mathrm{L}_{\mathrm{s}}} \mathrm{P}-\omega \mathrm{Q}-\frac{3 \mathrm{~V}_{\mathrm{dc}} \mathrm{V}_{\mathrm{m}}}{4 \mathrm{~L}_{\mathrm{s}}} \mathrm{m}_{\mathrm{qs}}+\frac{3 \mathrm{~V}_{\mathrm{m}}^{2}}{2 \mathrm{~L}_{\mathrm{s}}} \\
p \mathrm{Q}=\omega \mathrm{P}-\frac{\mathrm{R}_{\mathrm{s}}}{\mathrm{L}_{\mathrm{s}}} \mathrm{Q}-\frac{3 \mathrm{~V}_{\mathrm{dc}} \mathrm{V}_{\mathrm{m}}}{4 \mathrm{~L}_{\mathrm{s}}} \mathrm{m}_{\mathrm{ds}} \\
p \mathrm{~V}_{\mathrm{dc}}=\frac{1}{2 \mathrm{~V}_{\mathrm{m}} \mathrm{C}_{\mathrm{dc}}}\left(\mathrm{m}_{\mathrm{qs}} \mathrm{P}+\mathrm{m}_{\mathrm{ds}} \mathrm{Q}\right)-\frac{\mathrm{d}_{1}}{\mathrm{C}_{\mathrm{dc}}} \mathrm{i}_{\mathrm{b}} \\
p \mathrm{i}_{\mathrm{b}}=-\frac{1}{\mathrm{~L}_{\mathrm{o}}}\left(\mathrm{v}_{\mathrm{b} 1}+\mathrm{v}_{\mathrm{b}}\right)-\frac{\mathrm{R}_{\mathrm{o}}+\mathrm{R}_{2}}{\mathrm{~L}_{\mathrm{o}}} \mathrm{i}_{\mathrm{b}}+\frac{\mathrm{d}_{1}}{\mathrm{~L}_{\mathrm{o}}} \mathrm{V}_{\mathrm{dc}} \\
p \mathrm{v}_{\mathrm{b} 1}=\frac{1}{\mathrm{C}_{1}} \mathrm{i}_{\mathrm{b}}-\frac{\mathrm{v}_{\mathrm{b} 1}}{\mathrm{R}_{1} \mathrm{C}_{1}} \\
p \mathrm{v}_{\mathrm{b}}=\frac{1}{\mathrm{C}_{2}} \mathrm{i}_{\mathrm{b}}-\frac{\mathrm{v}_{\mathrm{b}}-\mathrm{V}_{\mathrm{oc}}}{\mathrm{R}_{2} \mathrm{C}_{2}}
\end{array}
$$

where $p=\frac{\mathrm{d}}{\mathrm{dt}} ; \mathrm{m}_{\mathrm{qs}}, \mathrm{m}_{\mathrm{ds}}$ are the qd modulation indices of the ac-to-dc converter and $d_{1}$ is the duty ratio of switching device.

At steady state, $p x=0$ where $x$ are the states. Hence solving (10) - (15)

$$
\begin{gathered}
\mathrm{m}_{\mathrm{qs}}=\frac{4 \mathrm{~L}_{\mathrm{s}}}{3 \mathrm{~V}_{\mathrm{dc}} \mathrm{V}_{\mathrm{m}}}\left[-\frac{\mathrm{R}_{\mathrm{s}} \mathrm{P}}{\mathrm{L}_{\mathrm{s}}}-\omega \mathrm{Q}+\frac{3 \mathrm{~V}_{\mathrm{m}}^{2}}{2 \mathrm{~L}_{\mathrm{s}}}\right] \\
\mathrm{m}_{\mathrm{ds}}=\frac{4 \mathrm{~L}_{\mathrm{s}}}{3 \mathrm{~V}_{\mathrm{dc}} \mathrm{V}_{\mathrm{m}}}\left[\omega \mathrm{P}-\frac{\mathrm{R}_{\mathrm{s}}}{\mathrm{L}_{\mathrm{s}}} \mathrm{Q}\right] \\
\mathrm{R}_{\mathrm{T}} \mathrm{i}_{\mathrm{b}}^{2}+\mathrm{V}_{\mathrm{oc}} \mathrm{i}_{\mathrm{b}}-\frac{\mathrm{V}_{\mathrm{dc}}}{2 \mathrm{~V}_{\mathrm{m}}}\left(\mathrm{m}_{\mathrm{qs}} \mathrm{P}+\mathrm{m}_{\mathrm{ds}} \mathrm{Q}\right)=0 \text {, where } \mathrm{R}_{\mathrm{T}} \\
=\mathrm{R}_{1}+\mathrm{R}_{2}+\mathrm{R}_{\mathrm{o}}+\mathrm{R}_{\mathrm{b}} \\
\mathrm{d}_{1}=\frac{\mathrm{R}_{\mathrm{T}} \mathrm{i}_{\mathrm{b}}}{\mathrm{V}_{\mathrm{dc}}}+\frac{\mathrm{V}_{\mathrm{oc}}}{\mathrm{V}_{\mathrm{dc}}} \\
\mathrm{v}_{\mathrm{b} 1}=\mathrm{R}_{1} \mathrm{i}_{\mathrm{b}} \quad \text { and } \mathrm{v}_{\mathrm{b}}=\mathrm{R}_{\mathrm{b}} \mathrm{i}_{\mathrm{b}}+\mathrm{V}_{\mathrm{Oc}}
\end{gathered}
$$

\section{RESULTS AND DISCUSSION}

The steady state analysis is done for battery state of chage (SOC) $=0.5$. The system parameters are shown in Table 1.

Table 1: System Parameters.

\begin{tabular}{cccc}
\hline Parameter & Value & Parameter & Value \\
\hline $\mathrm{f}_{\mathrm{s}}$ & $60 \mathrm{~Hz}$ & $\mathrm{R}_{\mathrm{O}}$ & $9.5 \mathrm{~m} \Omega$ \\
$\mathrm{V}_{\mathrm{l}}$ & $208 \mathrm{~V}$ & $\mathrm{R}_{\mathrm{b}}$ & $0.02402 \Omega$ \\
$\mathrm{Ls}$ & $2.5 \mathrm{mH}$ & $\mathrm{R}_{1}$ & $0.00824 \Omega$ \\
$\mathrm{R}_{\mathrm{s}}$ & $9.5 \mathrm{~m} \Omega$ & $\mathrm{R}_{2}$ & $0.00064 \Omega$ \\
$\mathrm{L}_{\mathrm{o}}$ & $15 \mathrm{mH}$ & $\mathrm{S}$ & $12.5 \mathrm{kVA}$ \\
\hline
\end{tabular}

Figure 2 shows the modulation indexes of the ac $-\mathrm{dc}$ converter as well as that of the $\mathrm{dc}-\mathrm{dc}$ converter while Figure 3 shows both the peak value of the grid current and the battery current. The results are obtained for a $\mathrm{dc}$ link capacitor value of $370 \mathrm{~V}$. The battery charger has a power rating of $12.5 \mathrm{kVA}$ and the results show the steady state values of the model variables within the range of the battery charger rating. Figure 2 (d) shows that the system operates within the linear region for the range of battery charger rating as the peak value of the modulation index for the three phase converter is less than one for the entire range of battery charger rating. The duty ratio of the $\mathrm{dc}-\mathrm{dc}$ converter shows operation within the linear region also. Figure 3 shows the current flow in the system and hence the flow of power. It shows that power can flow from the grid to the battery and that power flow in the opposite direction is also possible. Negative battery current shows the situation of real power support of the grid while positive battery current shows the case of the battery being charged. It is seen from Figure 3(b) that the battery current is unaffected by reactive power in the system as lines of battery current as lines of constant magnitude as long as the reactive power is concerned. The magnitudes of these lines change only with respect to change in active power. As the battery doesn't supply reactive power, the reactive power demand of the grid is supplied locally by the three phase converter. This is made possible by modulating the three phase converter to meet the demanded reactive power of the grid when required. This study has shown the possibility of vehicle to grid as well as grid to vehicle support. It has developed models which could ease the controller development of such systems. The actual physical implementation of grid to vehicle and vehicle to grid will depend on several factors including policies on for instance grid reactive power support.

\section{CONCLUSIONS AND FUTURE WORK}

A detailed steady state analysis of an off board bidirectional PEV charger has been presented. The analysis is presented for the entire possible range of operation and for given battery state of charge (SOC) rather than selecting points of operation a priori. In addition, the model of the system has been formulated in terms of the real and reactive power which variables are normally the objective of control. This result shows the various possibilities of the system and informs further structural studies of the system and the design of controllers to meet desired control objectives. Furthermore, this study has shown the possibility of vehicle to grid as well as grid to vehicle support. It has developed models which could ease the controller development of such systems. The actual physical implementation of grid to vehicle and vehicle to grid will depend on several factors including policies on for instance grid reactive power support. 

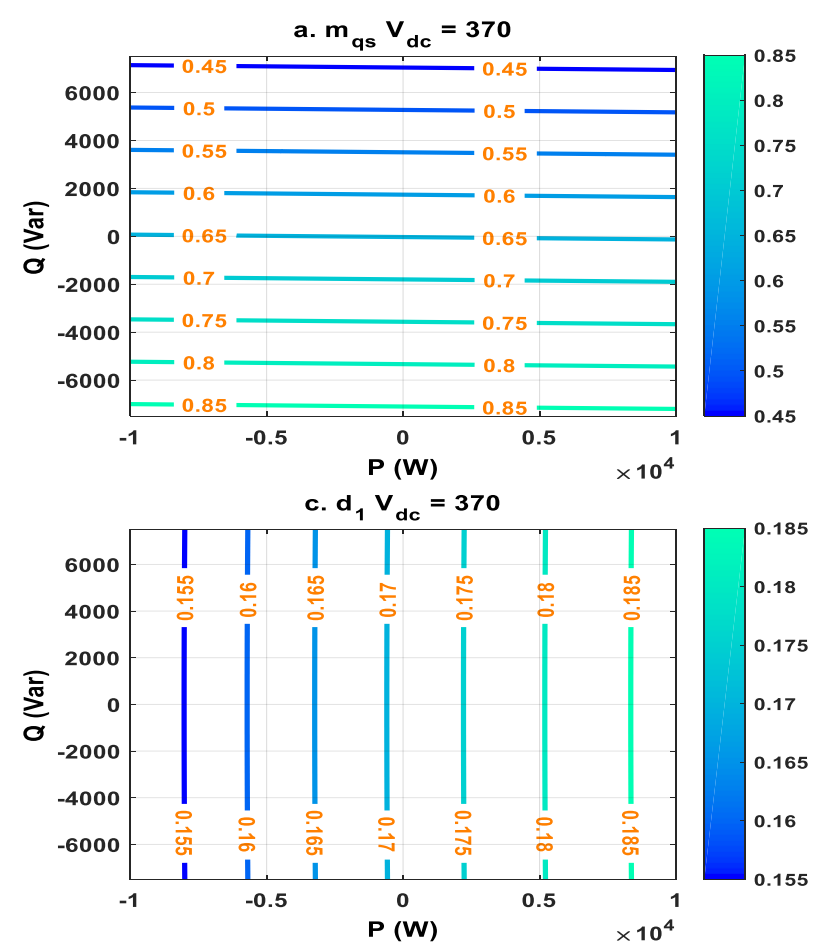
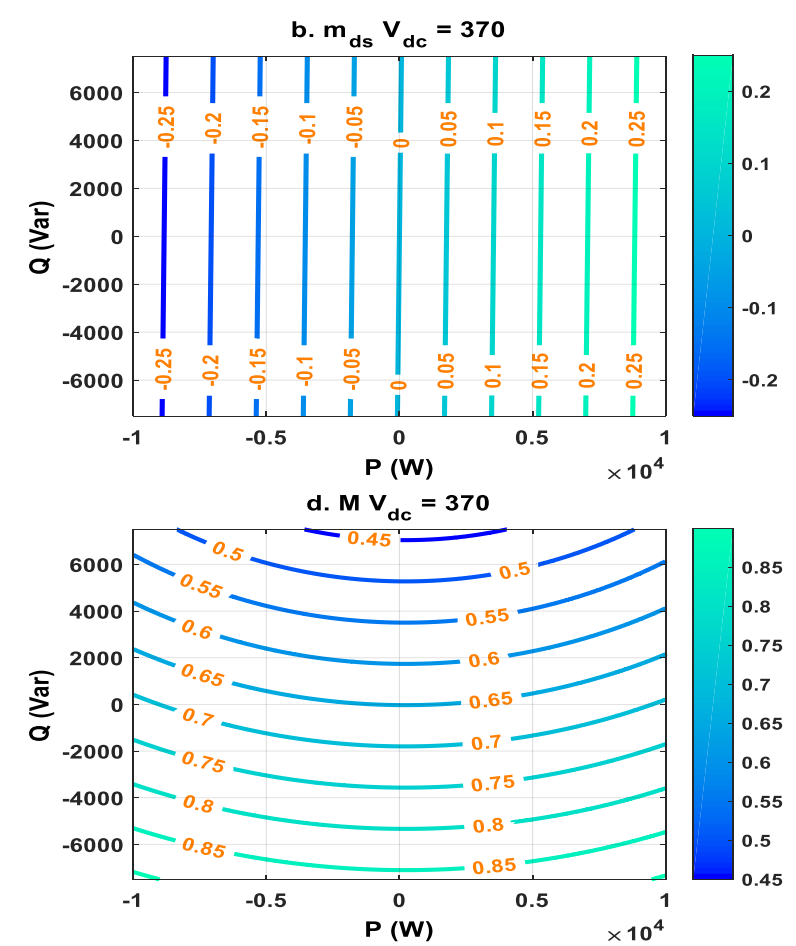

Figure 2: Modulation Index of Converters in the System. (a) $q$-axis modulation index of ac-dc converter (b) $d$ axis modulation index of ac-dc converter (c) duty ratio of dc-dc converter and (d) peak value of modulation index for ac-dc converter.
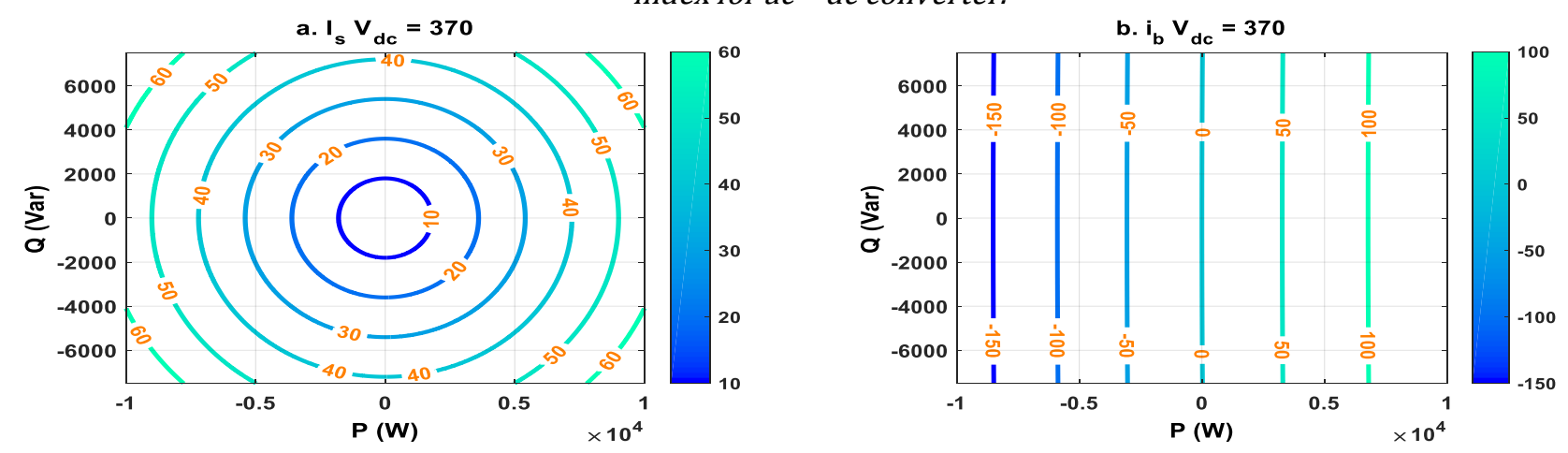

Figure 3: Current Flow in the System (a) Peak Source Current (b) Battery Current

\section{REFERENCES}

[1] International Energy Outlook 2011, U. S. Dept. Energy, Washington, DC, USA, Tech. Rep. OE/EIA-0484, Accessed on November 18, 2017.

[2] Kisacikoglu, M. C., Kesler, M., and Tolbert, L. M. "Single Phase On-Board Bidirectional PEV Charger for V2G Reactive Power Operation," IEEE Transactions on Smart Grid, Vol. 6, Number 2, pp. 767 - 775, 2015.

[3] Kesler, M., Kisacikoglu, M. C., and Tolbert, L. M. "Vehicle to Grid Reactive Power Operation Using Plug In Electric Vehicle Bidirectional Offboard Charger," IEEE Transactions on Endustrial Electronics, Vol. 61, Number 12, pp. 6778 - 5784, 2015.

[4] Xie, S., Zhong, W., Xie, K., Yu, R., and Zhang, Y. "Fair Energy Scheduling for Vehicle - to - Grid Networks Using Adaptive Dynamic Programming," IEEE
Transaction on Neural Networks and Learning Systems, Vol. 27, Number 8, pp. 1697 - 1707, 2016.

[5] Kumar Nunna, H. S. V. S., Battula, S., Doolla, S., and Srinivasan, D. "Energy Management in Smart Distribution Systems with Vehicle - to - Grid Integrated Microgrids," IEEE Transaction on Smart Grid, Volume: 9, Issue: 5, P. 4004 - 4016, Sept. 2018

[6] Krein, P. T., and Fasugba, M. A. "Vehicle-to-grid power system services with electric and plug-in vehicles based on flexibility in unidirectional charging." CES Transactions on Electrical Machines and Systems Vol. 1, Number 1, pp 26-362017.

[7] Hoang, D. T., Wang, P., Niyato, D., and Hossain, E. "Charging and Discharging of Plug-In Electric Vehicles (PEVs) in Vehicle-to-Grid (V2G) Systems: A Cyber Insurance-Based Model," IEEE Access, Vol. 5. 732-754, pp, 2017. 